УДК 575.174.015:635.26

(C) Н. Н. Рыжова ${ }^{1}$, Е. А. Дьяченко ${ }^{1}$, М. А. Вишнякова ${ }^{2}$, Е. 3. Кочиева ${ }^{1}$

${ }^{1}$ Центр «Биоинженерия» Российской академии наук, Москва

${ }^{2}$ Государственное научное учреждение Всероссийский научно-исследовательский институт растениеводства имени Н. И. Вавилова Российской академии сельскохозяйственных наук, г. Санкт-Петербург

\section{\& Впервые определены последовательности b/c интрона митохондриального гена $\mathrm{Nad1}$ у представителей 13 видов Vicia. Показано, что последовательность интрона гена Nad1 у исследованных представителей рода характеризуется высокой консервативностью. Всего было идентифицировано 23 вариабельных сайта и 11 инделей при длине интрона 1421-1447 п. н. По результатам фолдинга пре-мРНК интрона были определены основные элементы его вторичной структуры, а также сайты междоменных взаимодействий. Охарактеризованы особенности первичной и вторичной структуры интрона Nad1 у Vicia.}

\section{\& К Кючевые слова: интроны} II группы; пре-мРНК; автосплайсинг; вторичная структура; домены; точковые замены; индели; эволюция.

Поступила в редакцию 15.09.2010 Принята к публикации 22.02.2011

\section{ХАРАКТЕРИСТИКА ВАРИАБЕЛЬНОСТИ ИНТРОНА МИТОХОНДРИАЛЬНОГО ГЕНА NАD1 У ПРЕДСТАВИТЕЛЕЙ РОДА VICIA L. (CEM. FABACEAE LINDL.)}

\section{ВВЕДЕНИЕ}

Интроны II группы представляют собой ретроэлементы с рибозимной активностью, распространенные в геномах бактерий и органелл эукариот (митохондрий и пластид). Предположительно интроны этой группы сыграли ключевую роль в эволюции геномов многих организмов, участвуя в формировании генетического разнообразия (Koonin, 2006). Считается, что интроны II группы могут подставлять предков современной эукариотической сплайсосомы (Lambowitz and Zimmerly, 2004, Dai et al., 2008, Keating et al., 2010).

Bсе интроны II группы при сплайсинге образуют специфическую пространственную структуру, которая состоит из шести спиральных доменов (DI-DVI) и поддерживается более чем 14 молекулярными междоменными связями (Michel et al., 1989, Toor et al., 2001). Консервативность четвертичной структуры, присущая всем интронам II группы, обусловливает их точное вырезание и последующий сплайсинг экзонов гена (Dai et al., 2008). B вырезании интронов интронов II группы также участвует специфический белок матураза, закодированная последовательностью самого интрона.

Данные анализа первичной и вторичной структуры пре-мРНК интронов II, а также филогенетического анализа последовательности матуразы использовались для классификации интронов II группы. Все интроны II группы были разделены на три главных класса — IIA, IIB, IIC. В целом большинство интронов II митохондриального генома относят к классу IIA, а интроны II хлоропластного генома относят к классу IIB. (Michel et al. 1989; Toor et al., 2001; Lambowitz and Zimmerly, 2004)

K интронам класса IIA относят второй (b/c) интрон митохондриального гена Nad1, кодирующего первую субъединицу одного из ключевых белков дыхательной цепи NADH-дегидрогеназы. Ген Nadl состоит из пяти экзонов, которые разделяются последовательностями интронов или других генов (Won and Renner, 2003).

Қак и большинство интронов II органелл растений, b/с интрон митохондриального гена Nad1 исследован сравнительно слабо. Только недавно появились работы по использованию b/с интрона гена Nad1 в популяционном анализе у хвойных (Pinus, Cedrus), дуба Quercus robur (Burban and Petit, 2003; Qiao et al., 2007; Soranzo et al., 2000), а также в эволюционно-филогенетических и филогеографических исследованиях у Orchidaceae, Burmanniaceae, Araceae (Freudenstein and Chase, 2001; Won and Renner, 2003, 2006; Renner and Zhang, 2004). Однако все еще мало данных как о вариабельности первичной последовательности, так и о структурно-функциональных особенностях b/с интрона гена Nad1 у различных таксонов растений. Также до сих пор не ясно, насколько изменения в первичной структуре интрона влияют на его вторичную структуру и насколько вторичная структура b/с интрона гена Nad1 отличается от канонической структуры бактериальных интронов II. Носят ли эти изменения геномспецифический характер или являются характеристикой только этого интрона? В настоящее время только две работы касались структурно-функциональных особенностей этого интрона у растений. В одной из них было показано существование нескольких форм вырезаемого b/с интрона из пре-мРНК гена Nad1 у пшеницы (Li-PookThan and Bonen, 2006). В другой исследовались распределение, полиморфизм 
Таблиц̧а 1

Образцы рода Vicia и Lens взятые в анализ

\begin{tabular}{|c|c|c|c|c|c|}
\hline № & Образец/ вид & Номер каталога ВИР & Происхождение & Подрод & Секция \\
\hline 1 & $V$. sativa $L$. & 36653 & Московская обл. & Vicia & Vicia Kupicha \\
\hline 2 & V. angustifolia Reichard* & 35983 & Новгородская обл. & - " - & $-"-$ \\
\hline 3 & V. faba L. & 1628 & Украина & $-"$ & Faba (Mill.) Ledeb. \\
\hline 4 & V. bithunica L. & 32547 & Украина & $-"$ & $-"$ - \\
\hline 5 & V. narborensis $L$. & 36787 & Алжир & - " - & - " - \\
\hline 6 & V. michauxii Spreng. & 36721 & Армения & $-"$ & Peregrinae Kupicha \\
\hline 7 & $V$. peregrine $L$. & 36771 & Азербайджан & - " - & - " - \\
\hline 8 & V. pannonica Grantz & 34525 & Грузия & - " - & Hypechusa Kupicha \\
\hline 9 & V. unijuga A.Br. & 35828 & Новосибирская обл. & $\begin{array}{l}\text { Vicilla (Schur) } \\
\text { Rouy et Fouc. }\end{array}$ & $\begin{array}{c}\text { Vicilla (Schur) } \\
\text { Aschers. Et Graebn. }\end{array}$ \\
\hline 10 & V. hirsuta (L.) Gray & 36792 & Португалия & - " - & Cracca S.F.Gray \\
\hline 11 & V. villosa Roth & 37026 & Тамбовская обл. & $-"-$ & $-"$ \\
\hline 12 & $V$. benghalensis $L$. & 34852 & Португалия & - " - & $-"$ \\
\hline 13 & V. ervilia Willd & 517 & Украина & $-"$ & Ervilia(L.)Koch \\
\hline 14 & Lens culinaris Medik. & 224 & Воронежская обл. & & \\
\hline
\end{tabular}

и структурные особенности интронов этого гена, главным образом у нецветковых растений (печеночники, мхи, хвощи и др.) (Dombrovska and Qiu, 2004).

B настоящей работе для анализа полиморфизма и структурных особенностей интрона Nad1 были взяты представители обширного и гетерогенного рода Vicia (сем. Fabaceae). До настоящего времени у бобовых растений последовательности b/с интрона гена NadI были получены для некоторых видов, таких как Glycine max (AJ428875), Lupinus angustifolius (EU544944) и Jacksonia floribunda (EU544945) (GeneBank NCBI), однако сравнительного анализа, оценки полиморфизма и структурно-функционального анализа этих последовательностей не проводилось. Приблизительные границы и протяженность доменов пре-РНК интрона у Glycine max были описаны в работе при исследовании вопросов горизонтального переноса ДНК у голосеменных растений (Won and Renner, 2003).

Таким образом, целью данной работы стал анализ первичной и вторичной структуры b/с интрона гена Nad1 у представителей рода Vicia, предполагающий: 1 ) оценку уровня нуклеотидной вариабельности; 2) характеристику особенностей мутационных изменений b/c интрона гена NadI у представителей рода Vicia; 3) исследование возможного влияния детектированных изменений первичной последовательности ДНК интрона на топологию вторичной структуры пре-РНК.

\section{МАТЕРИАЛЫ И МЕТОДЫ}

В работе были использованы образцы 13 видов Vicia из коллекции ГНУ ВИР Россельхозакадемии (Санкт-Пе- тербург), представляющие семь секций двух подродов: Vicia и Vicilla по системе F. K. Kupicha (1976). В качестве внешней группы в анализ был взят образец вида Lens culinaris (табл. 1).

Экстракцию ДНК проводили из проростков по стандартной методике (Edwards et al., 1991). Амплификацию интрона гена Nadl проводили с праймерами, соответствующими концевым 3' - и 5' - последовательностям b и с экзонов гена Nad1 (Demesure et al., 1995). Первичные последовательности амплифицированных фрагментов были определены с помощью системы Big dye («Applied Biosystems», США) на ABI 310 cappilary DNA Analyzer. Выравнивание последовательностей производили с помощью программы MEGA 5.0. (Tamura et al., 2007).

Определения позиций точковых замен проводили на основе выровненной последовательности от первого нуклеотида интрона. Потенциально информативные характеристики (PIC, potential informative characters) pacсчитывалась как сумма общего числа инделей, замен и инверсий (Shaw et al., 2005). Для построения вторичных структур пре-мРНК интрона была использована программа MFOLD (Zuker, 2003).

\section{РЕЗУЛЬТАТЫ И ОБСУЖДЕНИЕ}

\section{Общая характеристика и полиморфизм последовательностей интрона гена Nad1 у представителей Vicia}

В результате амплификации для 13 видов рода Vicia и вида Lens culinaris были получены ПЦР продукты ожидаемой длины, секвенирование которых подтвердило 
специфичность амплификации и наличие b/c интрона в митохондриальном гене Nad1 у исследуемых образцов в позиции Nad1 I477(0) (Dombrovska and Qiu, 2004).

Длина интрона у взятых в анализ представителей рода Vicia варьировалась от 1421 п. н. (V. hirsuta) до 1447 п.н. (V. unjuga). Выровненная длина последовательностей интрона составила 1452 п. н. Всего было идентифицировано 11 инделей (1-7 п. н.) и 23 вариабельных нуклеотидных сайта, что позволило выявить 11 митотипов.

При этом наибольшее число потенциально информативных полиморфных характеристик PIC=7 было детектировано в последовательностях интрона $N a d 1$ у образцов вида V. ervilia (5 замен - G/ $\mathrm{T}_{129}, \mathrm{~A} / \mathrm{C}_{242}, \mathrm{C} / \mathrm{A}_{451}, \mathrm{C} / \mathrm{A}_{463}, \mathrm{G} / \mathrm{T}_{1185}$ и 2 индели ТСАССАА $\left.{ }_{1090-1096}, \mathrm{AACCT}_{1197-1202}\right)$, вида V. hirsuta (2 замены - $\mathrm{A} / \mathrm{C}_{632}, \mathrm{~A}_{854} / \mathrm{C}$ и 5 инделей - $\mathrm{GATTT}_{452-456}$, $\mathrm{GG}_{655-656}, \mathrm{~A}_{1202}$, CTTTC $_{1205-1209}$ TGACG $\left._{1346-1350}\right)$, а также у видов V. villosa (3 замены - $\left.\mathrm{T} / \mathrm{G}_{341}, \mathrm{~T} / \mathrm{G}_{627}, \mathrm{G} / \mathrm{T}_{766}\right)$ и $V$. faba (2 замены $-\mathrm{G} / \mathrm{T}_{128}, \mathrm{~T} / \mathrm{G}_{390}$ и индель $\mathrm{GCGG}_{150-153}$ ). Также были идентифицированы нуклеотидные замены и индели, специфичные для групп видов. Так, последовательности образцов $V$. hirsuta и $V$. ervilia характеризовались присутствием замен $\mathrm{C} / \mathrm{A}_{242}, \mathrm{G} / \mathrm{A}_{1411}$ и индели $\mathrm{AACCG}_{1255-1259}$. Никаких различий не было детектировано между последовательностями интрона видов $V$. sativa и $V$. angustifolia, а также образцов видов $V$. pannonica и $V$. benghalensis. В целом, детектированный полиморфизм b/с интрона гена Nad1 у видов вик можно охарактеризовать как низкий. Рассчитанные коэффициенты различий не превышали 0,008 .

Максимальные различия были детектированы между митотипами $V$. ervilia/V. hirsuta и остальными Vicia. Выделение $V$. hirsuta и V. ervilia как наиболее дивергентных таксонов рода Vicia отмечалась и ранее при анализе нуклеотидного полиморфизма внутренних транскрибируемых спейсеров (ITS) ядерных рибосомных генов (Рыжова и др., 2007), а также по данным анализа последовательностей хлоропластного генома (неопубликованные данные). Интересно отметить, что таксономическое положение проблематичных видов $V$. hirsuta и V. ervilia, не раз подвергалось пересмотру с предложением о выделении этих видов в отдельные родовые ранги Ervum и Ervilia (Alefeld, 1861; Станкевич, Репьев, 1999).

Последовательность интрона Lens culinaris, наиболее близкородственного для рода Vicia, не имела специфичных инделей, однако отличалась 8 нуклеотидными заменами.

Анализ типов замен и нуклеотидного состава анализируемых последовательностей интрона Nad1 показал преобладание трансверсии типа $\mathrm{G} \leftrightarrow \mathrm{T}$ с преимущественной локализацией замен в области петель доменов. Содержание G/C пар в последовательности b/с интрона Nad1 у исследованных образцов Vicia в среднем составило 53,9\%, что соответствовало ранее известным данным о G/C составе интрона у растений (Burban and Petit, 2003, Рыжова и др., в печати)
Анализ полученных первичных последовательностей b/c интрона Nad1 у исследованных образцов рода Vicia показал, что число идентифицированных точковых замен превышало число инделей в 2 раза, в то время как по данным J. Laroche и др. (1997) в интронах митохондриальных генов растений нуклеотидные замены встречаются в пять раз чаще, чем индели. Однако более поздние данные по Gnetum (Won and Renner, 2003), Araceae (Renner, Zhang, 2004), Pinus (Burban and Petit, 2003), Orhidaceae (Freudenstein and Chase, 2001) указывают на насыщенность интронов II типа различными типами инделей, причем не только у дальнеродственных, но и у близкородственных таксонов.

Интересно отметить, что все индели, идентифицированные у видов Vicia, главным образом представляли $4-5$ нуклеотидные повторы и были обусловлены тандемной дупликацией/делецией смежного участка. В сравнении с Vicia длина инделей, например, в интроне Nad1 у чеснока A. sativum (сем. Alliaceae, однодольные), достигала 28 нуклеотидов и только в единичных случаях детектированные индели были ассоциированы с дупликацией смежного участка (Рыжова и др., в печати).

Различные типы инделей связывают с различными механизмами их образования. Так, считается, что более 50 \% коротких инделей $(1-10$ п. н.) являются результатом проскальзывания ДНК-полимеразы при репликации, в то время как образование более протяженных инделей обусловлено механизмами рекомбинации более дистанцированных участков петельно-шпилечных структур ДНК. Такой тип инделей, как правило, характерен для самосплайсирующихся интронов, а также последовательностей, функция которых связана с образованием сложных вторичных структур (Laroche et al., 1997; Kelchner, 2000).

Таким образом, получены и охарактеризованы последовательности b/c интрона митохондриального гена Nad1 у образцов 13 видов рода Vicia. Показана высокая консервативность этого интрона у Vicia. Идентифицированы ряд таксонспецифичных инделей и нуклеотидные замены, которые могут быть использованы в качестве молекулярных ДНК-маркеров для видовой идентификации виковых.

\section{Полиморфизм отдельных участков b/c интрона у представителей трибы Vicieae рода Vicia}

Поскольку вторичная структура интронов II имеет существенное значение для сплайсинга гена, содержащего данный интрон, отдельный интерес в работе представляло исследование полиморфизма отдельных частей интрона, закономерности распределения мутации на протяжении интрона и выявления предположительно наиболее функционально важных участков на основе их консервативности. 
Таблица 2

Характеристика последовательности b/с интрона гена Nad1 образцов рода Vicia

\begin{tabular}{|l|c|c|c|c|c|c|c|}
\hline Vicia (13) & I домен & II домен & III домен & IV домен & V домен & VI домен & $\begin{array}{c}\text { Интрон } \\
\text { I-VI домены }\end{array}$ \\
\hline Длина п. н. & $280-284$ & $177-182$ & 106 & $782-803$ & 34 & 15 & $1421-1447$ \\
\hline Выровненная длина п. н. & 284 & 182 & 106 & 808 & 34 & 15 & 1452 \\
\hline GC состав, \% & 56,7 & 48,8 & 56,7 & 52,9 & 55,9 & 86,7 & 53,9 \\
\hline Число SNP & 4 & 8 & 0 & 9 & 2 & 0 & 23 \\
\hline Число инделей & 1 & 1 & 0 & 9 & 0 & 0 & 11 \\
\hline $\begin{array}{l}\text { Число полиморфных } \\
\text { признаков (SNP + индели) }\end{array}$ & 5 & 9 & 0 & 18 & 2 & 0 & 34 \\
\hline
\end{tabular}

Данные о первичных последовательностях интрона, а также данные фолдинга интрона Nad1 у 13 исследованных видов Vicia позволили идентифицировать границы всех шести доменных участков, а также основные консервативные и полуконсервативные мотивы, определяющие пространственную структуру интрона и его каталитическую активность, согласно моделям F. Michel и др. (1989), N. Тоог и др. (2001) .

Домен I у представителей Vicia составил около 20 \% длины всего интрона. Протяженность его последовательности варьировалась от 280 до 284 п. н., что было обусловлено 4 нуклеотидной делецией у $V . f a b a$. В целом последовательность этого домена была высоко консервативна. Помимо делеции $\mathrm{GCGG}_{150-153}$ у $V$. faba в этом домене было идентифицировано 4 вариабельных сайта (табл. 2). Сравнительно высокую консервативность (1,4\% полиморфных сайта) домена I связывают с его функциональной значимостью для сплайсинга гена $\mathrm{Nad} 1$, а также для формирования ключевых молекулярных связей с сайтами основного кольца интрона и доменом $\mathrm{V}$ для образования коровой каталитической четвертичной структуры (Kelchner, 2002) (рис. 1).

Известно, что последовательность этого домена в общей сложности задействована как минимум в 10 междоменных связях и насыщена целым рядом консервативных и полуконсервативных мотивов, которые были идентифицированы в анализируемых последовательностях b/c интрона Nad1 у Vicia. (рис. 1.)

Все исследованные последовательности на 5' конце содержали консервативный мотив GUGCG (канонический GYGCG) с сайтами для $\lambda-\lambda$ ' и $\varepsilon-\varepsilon$ ' взаимодействия c IC и V доменами. Также все последовательности на 3'-конце несли мотив ТАТ, который соответствовал каноническому для интронов группы IIA - YAY (Michel et al., 1989, Toor et al., 2001). B I домене интрона Nad1 y всех представителей Vicia были идентифицированы субдомены IA, IC, ID (рис. 1.). Домен IB отсутствовал. IC субдомен формировал только шпильку IC1. Также отсутствовала шпилька IC2 с мотивом для $\beta$-взаимодействия. У видов Vicia также отсутствовала выраженная шпиль- ка ID(ii)a, а ее мотив образовывал внутреннюю петлю в стебле ID(ii). В субдомене ID идентифицированы потен-

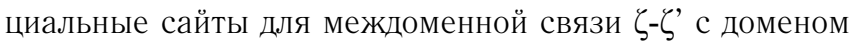
$\mathrm{V}$ и сайт EBS1 (exon binding site) для интрон-экзного взаимодействия с IBS1 (intron binding site). Точная локализация сайтов для к-к' и EBS2-IBS2 связей не определялась. В предположительной области локализации EBS2 отмечался нуклеотидный полиморфизм и низкая термодинамическая стабильность. Фолдинг этой области характеризовался нестабильностью. В домене I также обнаружены структурные элементы, ранее не описанные для этого типа интронов. Это - внутренние петли в шпильке IC1, в основании стебля поддомена ID(i) и в стебле предполагаемой петли ID2 (рис. 1.).

Домен II у представителей Vicia составил 12,5\% длины b/с интрона Nad1, его длина варьировалась в пределах 177-182 п. н. Последовательность этого домена была несколько более полиморфной у исследуемых видов Vicia, чем последовательность домена I. В домене II было идентифицировано 8 вариабельных нуклеотидных позиций и делеция GATTT ${ }_{452-456}$, характеризовавшая митотип образца $V$. hirsuta (табл. 2). Считается, что роль этого домена в сплайсинге менее значима и его структурный полиморфизм может быть высоким. Например, у представителей рода Gnetum протяженность последовательности домена за счет инделей разной длины варьируется от 383 до 994 п. н. (Won and Renner, 2003).

Домен III. Последовательность III домена для всех исследованных представителей рода Vicia была инвариабельна и составила 106 нуклеотидов (табл. 2). При высокой консервативности домена его функция до сих пор остается не вполне ясной. Однако известны примеры и его полного отсутствия, как, например, в интроне хлоропластного гена rpS16 у ряда видов Allium (Рыжова и др., 2009).

Домен IV. Наиболее протяженный домен IV y Viciae имеет длину 782-803 п. н., что составляет более 55 \% последовательности полноразмерного b/c интрона Nad1. Последовательность этого домена характеризовалась наибольшим уровнем полиморфизма, в ней 
A

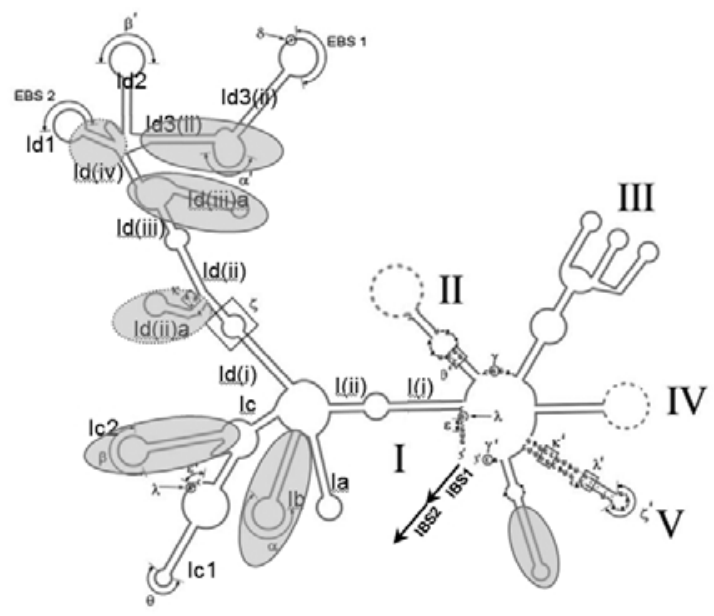

Б

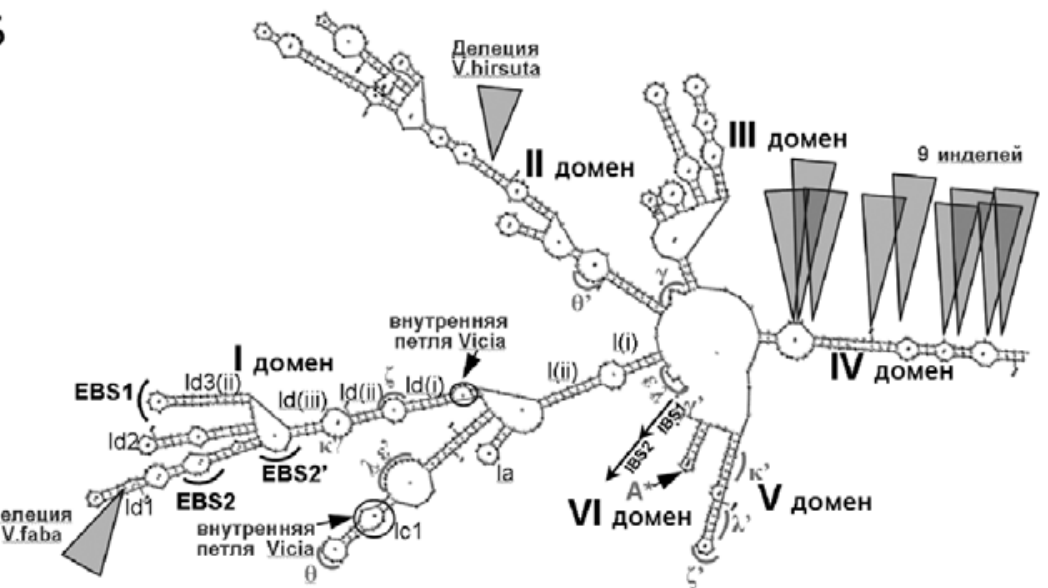

Рис. 1. А - схема пространственной вторичной структуры пре-мРНК интронов II (по Hausner et al., 2006). В овалах — наиболее вариабельные области/структуры интрона, которые могут отсутствовать у отдельных таксономических групп; Б - схема пространственной вторичной структуры пре-мPHK b/с интрона гена Nad1 у представителей рода Vicia. Треугольниками обозначены локализации идентифицированных делеций и инсерций; греческими буквами обозначены сайты междоменных взаимодействий ( $\varepsilon-\varepsilon^{\prime}, \zeta-\zeta^{\prime}, \lambda-\lambda$ ', $\kappa-\kappa^{\prime}, \theta-\theta$ '), стабилизирующих четвертичную структуру пре-мРНК интрона; стрелками обозначены структурные элементы, ранее не описанные для этого типа интронов. Также обозначены EBSs (exon binding sites) и IBSs (intron binding sites) сайты интрон-экзного взаимодействия

было детектировано 9 вариабельных сайтов и 9 инделей (табл. 2). Высокая вариабельность этого домена отмечается для большинства интронов II типа у различных таксономических групп как высших, так и низших эукариот, а также бактерий (Freudenstein and Chase, 2001, Won and Renner, 2003, Lohne and Borsch, 2005, Hausner et al., 2006). Вариабельность длин этого домена и точковый полиморфизм даже у близкородственных видов одного рода может достигать значительных размеров, как, например, у некоторых голосеменных (Won and Renner, 2003) или цветковых (Freudenstein and Chase, 2001). В среднем у покрытосеменных растений длина домена IV может варьироваться от 239 до 979 п. н. (Won and Renner, 2003).

Накопление различного рода мутаций в IV домене связывают с утратой его функциональной значимости, в особенности у высших эукариот. Известно, что в предко- вых генах, содержащих самосплайсирующиеся интроны, домен IV кодировал фермент матуразу, обеспечивающий вырезание интрона (Kelchner, 2002). Так, показано, что практически все бактериальные интроны II, идентифицированные до настоящего времени, содержат открытую рамку считывания (OPC) для этого белка (Zimmerly et al., 2001, Lambowitz and Zimmerly, 2004). У высших растений известно только два интрона, кодирующих матуразу, - matK и matR. Остальные 38 интронов полностью или частично утратили ОРС (Kelchner, 2002).

Домены V и VI. Последовательности доменов V и VI у Vicia характеризовались наименьшей длиной (34 п. н и 15 п. н.) и наибольшей консервативностью, что связано с ролью этих доменов в позиционировании всех структур пре-мРНК интрона и формировании каталитически активной пространственной структуры интрона (Kelchner, 2002). 


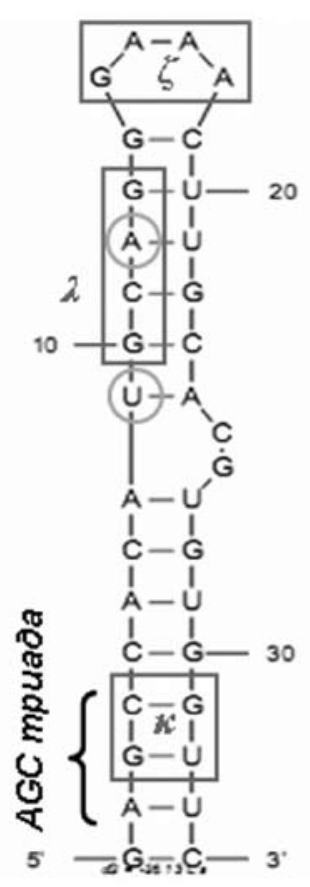

A. V. villosa (U9*)

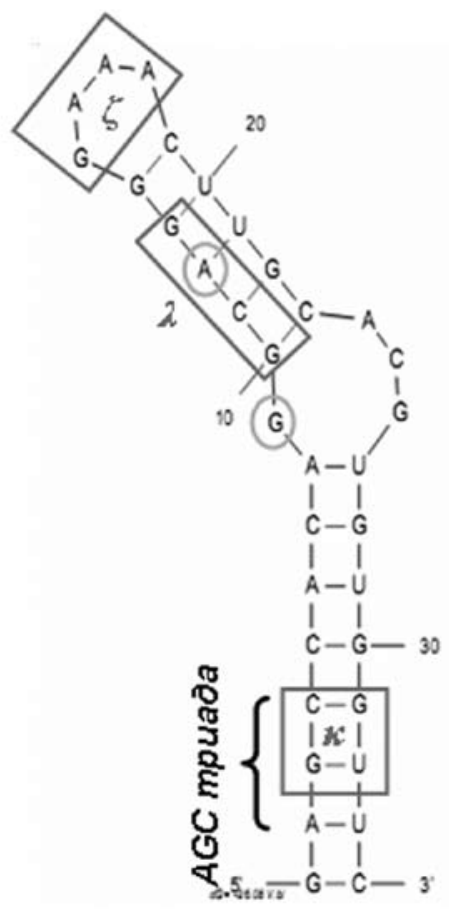

B. V. bithynica (G/U9*)

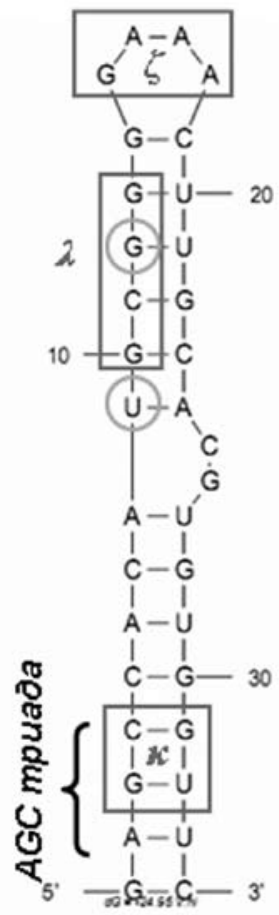

C. V. hirsuta/V. ervilia (G/A12*)

Рис. 2. Домен V b/с интрона митохондриального гена Nad1. В кругах - сайты нуклеотидных замен, прямоугольники РНК-мотивы, участвующие в междоменных взаимодействиях (к-к', $\lambda-\lambda$ ', $\left.\zeta-\zeta^{\prime}\right)$

В области V домена были идентифицированы всего две замены: у $V$. bithynica $\mathrm{G} / \mathrm{U}_{1408 / 9}$, и $\mathrm{G} / \mathrm{A}_{1411 / 12^{*}}$ у $V$. hirsuta/ V. ervilia (рис. 2). Согласно результатам фолдинга замена $\mathrm{G} / \mathrm{U}_{1408 / 9 *}$ у V. bithynica локализовалась в области внутренней петли и несколько меняла ее топологию, при этом, однако, положение функционально значимых активных нуклеотидов ACG, образующих каталитически активное выпетливание V домена, не изменялось. Другая замена $\mathrm{G} / \mathrm{A}_{1411 / 12^{*}}$ у $V$. hirsuta и V. ervilia входила в состав консервативного мотива верхнего стебля домена $\mathrm{V}$ и также не приводила к изменению в топологии домена (рис. 2).

Необходимо отметить, что известны примеры более значительных изменений первичной и вторичной структуры этого домена как в области AGC-триады, так и в области внутренней петли, и вплоть до частичной утраты этого домена, например, в интроне хлоропластных генов rpS16 у Allium (Рыжова и др., 2009) или в интроне trnK у различных классов наземных растений (Hausner et al., 2006).

Несмотря на то что в последовательности VI домена интрона $N a d I$ не было детектировано ни одной замены, его топология несколько отличалась от топологии в канонических моделях интронов II (рис. 3) (Michel et al., 1989 и Toor et al., 2001).

Согласно каноническим моделям, в интронах II критичный для первой стадии сплайсинга и запуска реакции трансэтерификации свободный аденозин занимает 8 позицию относительно 3'-конца интрона и локализуется в стебле домена VI (Michel et al., 1989; Toor et al., 2001). По результатам проведенного анализа единственный аденозин в коротком 15-нуклеотидном домене интрона гена занимает 10 позицию от 3' -конца интрона и локали зуется в области терминальной петли, оставаясь все же неспаренным (рис. 1 б и 3 ).

Аналогичная ситуация была описана у b/c интрона митохондриального гена Nad1 пшеницы, который также формировал плотную короткую шпильку с отсутствием в 8 позиции неспаренного аденозина (Li-Pook-Than and Bonen, 2006). Известны и другие примеры структурных изменений VI домена у интронов II растений, в том числе полное отсутствие не спаренного аденозина в домене VI интрона $\operatorname{trn} V$ у ячменя (Vogel and Borner, 2002) или же низкая термодинамическая стабильность домена VI в результате неправильно спаренных пар оснований (А:A, $\mathrm{G}: \mathrm{G}$ ) в интронах генов сох2, Nad1, Nad4 пшеницы (Farre and Araya, 2002, Li-Pook-Than and Bonen, 2006). Показано, что мутации такого типа, и в особенности мутации, затрагивающие точку ветвления - неспаренный аденозин, - приводят к изменению механизма сплайсинга. Реакция трансэтерификации замещается гидролитическим расщеплением, в результате которого интрон вырезается не в виде «лассо» (циркулярная молекула с 6-7 нуклеотидным хвостом), а в виде линейной молекулы. 


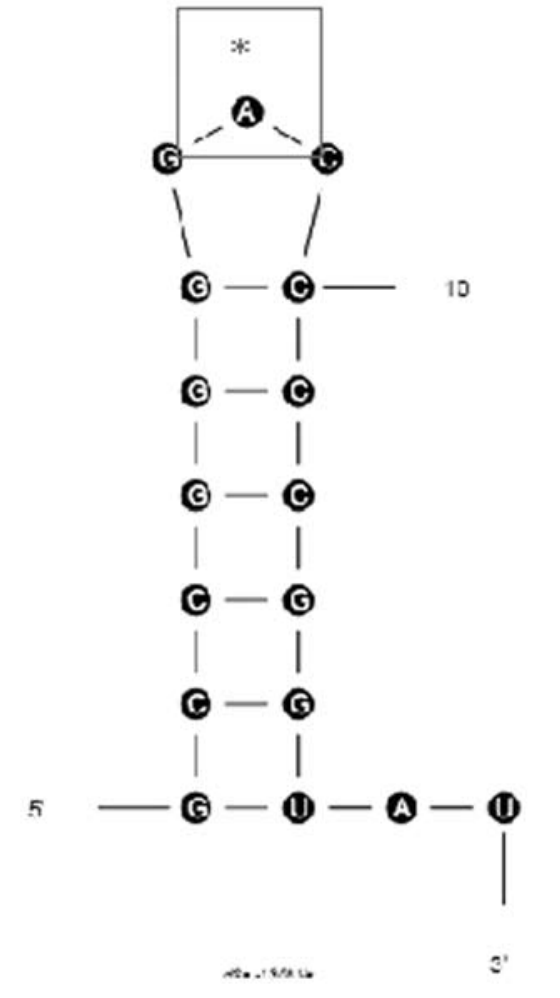

Рис. 3. VI домен b/с интрона гена Nad1 у Vicia

В некоторых случаях это приводит к некорректному выбору 3'-сайта сплайсинга и образованию популяции молекул различной длины (Vogel and Borner, 2002; MolinaSanchez et al., 2006). Действительно, было показано, что интрон хлоропластного гена $\operatorname{trn} V$ с отсутствующим свободным аденозином в стебле VI домена в процессе эксцизии образует линейные формы, которые возможны только при гидролитическом механизме эксцизии (Vogel and Borner, 2002). При вырезании b/с интрона митохондриального гена Nad1 пшеницы наряду с кольцевыми молекулами вырезанного интрона были идентифицированы и линейные молекулы различной длины, также указывая на гидролитический механизм вырезания этого интрона (Li-Pook-Than and Bonen, 2006).

Таким образом, согласно полученным данным b/c интрон митохондриального гена Nad1 у представителей рода Vicia содержит все шесть ключевых доменов и по большинству признаков может быть отнесен к IIA подклассу самосплайсирующихся интронов. В I домене интрона Nad1 у всех представителей Vicia были идентифицированы структуры IA, IC1, ID (ID(i), ID(ii), ID2, ID3), а также мотивы для $\varepsilon-\varepsilon^{\prime}, \lambda-\lambda, \theta^{\prime}, \theta^{\prime}$, IBS1-EBS1 междоменных взаимодействий. Детектированные в $\mathrm{V}$ домене нуклеотидные замены не изменяли топологии этого наиболее каталитически важного для сплайсинга домена. В 15-нуклеотидном VI домене единственный свободный аденозин, играющий ключевую роль в запуске реакции трансэтерификации, занимал нетипичную 10 позицию от 3'-конца интрона и локализовался в области терми- нальной петли. В целом первичная нуклеотидная последовательность и топология вторичных структур b/c интрон гена Nad1 у представителей рода Vicia характеризовались значительной консервативностью.

Работа была выполнена при частичной финансовой поддержке грантов РФФИ № 09-04-00574-а, № 11 -0400573-а, а также программы «Молекулярная и клеточная биология».

\section{Литература}

1. Рыжова Н. Н. Структурные особенности интрона гена rps16 у представителей Allium sativum и родственных видов Allium / Рыжова Н. Н., Холда О. А., Кочиева Е. 3. // Молекулярная биология. 2009. Т. 43. № 5. C. $1-11$.

2. Станкевич А. К. Вика. Культурная флора / Станкевич А. К., Репьев С. И. // Ред. Репьев С. И. СПб.: ГНЦ-ВИР, 1999. Т. 4.491 с.

3. Alefeld. F. Genus Vicia L. / Alefeld. F. // Bonpandia. 1861. Vol. 9. P. 66-199.

4. Bonen L. Cis- and trans-splicing of group II introns in plant mitochondria/Bonen L. // Mitochondrio N. 2006. Vol. 8. P. 26-34.

5. Burban C. Phylogeography of maritime pine inferred with organelle markers having contrasted inheritance / Burban C., Petit R. J. // Molecular Ecology. 2003 Vol. 12. P. 1487-1495.

6. Dai L. A three-dimensional model of a group II intron RNA and its interaction with the intron-encoded reverse transcriptase / Dai L., Chai D., Gu S. Q., Gabel J., Noskov S. Y., Blocker F. J., Lambowitz A. M., Zimmerly S., // Mol Cell. 2008. Vol. 30. P. 472-485.

7. Davis C. C. Gene transfer from a parasitic flowering plant to a ferN. / Davis C. C., Anderson W. R. and Wurdack K. J. // Proc. R. Soc. 2005. Vol. 272. P. 2237-2242.

8. Davis C. C. Host-to-parasite gene transfer in flowering plants: Phylogenetic evidence from Malpighiales / Davis C. C., Wurdack K. J. // Science. 2004. Vol. 305. P. 676-678.

9. Demesure B. A set of universal primers for amplification of polymorphic non-coding regions of mitochondrial and chloroplast DNA in plants / Demesure B., Sodzi N., and Petit R. J. // Mol. Ecol. 1995. Vol. 4. P. 129-131.

10.Dombrouska O. Distribution of introns in the mitochondrial gene Nad1 in land plants: phylogenetic and molecular evolutionary implications / Dombrovska, O., Qiu, Y. L. // Mol. Phylogenet. EVol.2004. Vol. 32. P. 246-263.

11.Edwards S. K. Simple and rapid method for the preparation of plant genomic DNA for PCR analysis / Edwards S. K., Thompson J. C. // Nucleic Acids Res. 1991. Vol. 19. P. 1349.

12.Farre J. C. RNA splicing in higher plant mitochondria: determination of functional elements in group II intron 
from a chimeric cox II gene in electroporated wheat mitochondria / Farre J. C., Araya A. // Plant J. 2002. Vol. 29. P. 203-213.

13. Freudenstein J. V. Analysis of mitochondrial nad1b-c intron sequences in Orchidaceae: utility and coding of lengthchange characters / Freudenstein J. V., Chase M. W. // Systematic Botany. 2001. Vol.26. P. 643-657.

14. Hausner $G$. Origin and evolution of the chloroplast trnK (matK) intron: a model for evolution of group II intron RNA structures / Hausner G., Olson R., Simon D., Johnson I., Sanders E. R., Karol K. G., McCourt R. M., Zimmerly S. // Mol. Biol. EVol.2006. Vol.23. P.380391.

15.Keating K.S. A structural analysis of the group II intron active site and implications for the spliceosome / Keating K. S., Toor N., Perlman P. S., Pyle A. M. // RNA. 2010. Vol. 16. P. $1-9$

16. Kelchner $S$. A. The evolution of noncoding chloroplast DNA and its application in plant systematics / Kelchner S. A. // Annals of the Missouri Botanical Gardens. 2000. Vol. 87. P. 482-498.

17.Kelchner $S$. A. Group II introns as phylogenetic tools: structure, function and evolutionary constraints / Kelchner S. A. // American Journal of Botany. 2002. Vol. 89. P. $1651-1669$.

18. Keren I. AtnMat2, a nuclear-encoded maturase required for splicing of group-II introns in Arabidopsis mitochondria / Keren I., Bezawork-Geleta A., Kolton M. et al. // RNA. 2009. Vol. 15. P. 2299-2311

19.Koonin E. $V$. The origin of introns and their role in eukaryogenesis: A compromise solution to the intronsearly versus introns-late debate? / Koonin E. V. // Biol Direct. 2006. Vol. 1. P. 1-23.

20.Kupicha F. K. The infrageneric structure of Vicia. / Kupicha F. K. // Notes from the Royal Botanic Garden. Edinburg. 1976. Vol. 34. N 3. P. 287-326.

21.Lambowitz A. M. Mobile group II introns / Lambowitz A. M., Zimmerly S. // Annu Rev Genet. 2004. Vol. 38. P. 1-35.

22. Laroche $J$. Molecular evolution of angiosperm mitochondrial introns and exons / Laroche J., Li P., Maggia L., Bousquet J. // Proc Natl Acad Sci USA. 1997. Vol. 94. 5722-5727.

23.Lencastre A. Three essential and conserved regions of the group II intron are proximal to the 59-splice site / Lencastre A., Pyle A. M. // RNA. 2008. Vol. 14. P. 11 24.

24.Li-Pook-Than J. Multiple physical forms of excised group II intron RNAs in wheat mitochondria / Li-PookTha, J., Bonen L. // Nucleic Acids Res. 2006. Vol. 34. P. 2782-2790.

25.Lohne C. Molecular evolution and phylogenetic utility of the petD group II intron: a case study in basal angio- sperms / Lohne C., Borsch T. // Mol. Biol. EVol. 2005. Vol. 22. P. 317-332.

26. Michel F. Comparative and functional anatomy of group II catalytic introns a review / Michel F., Umesono K., Ozeki H., // Gene. 1989. Vol.82. P.5-30.

27.Molina-Sanchez M. D. Excision of the Sinorhizobium meliloti group II intron RmIntl as circles in vivo / Molina-Sanchez M. D., Martinez-Abarca F., Toro N.// J. Biol. Chem. 2006. Vol. 281. P. 2873728744.

28. Nakagawa N. A mutation in At-nMatla, which encodes a nuclear gene having high similarity to group II intron maturase, causes impaired splicing of mitochondrial NAD4 transcript and altered carbon metabolism in Arabidopsis thaliana / Nakagawa N., Sakurai N.// Plant Cell. Physiol. 2006. Vol. 47. P.772-783.

29. Qiao C. Y. Phylogeny and Biogeography of Cedrus (Pinaceae) Inferred from Sequences of Seven Paternal Chloroplast and Maternal Mitochondrial DNA Regions / Qiao C. Y., Ran J. H., Li Y., Wang X. Q. // Annals of Botany. 2007. Vol. 100. N. 3. P. 573-580.

30. Renner S. S. Biogeography of the Pistia clade (Araceae) based on cp and mtDNA sequences and Bayesian divergence time inference / Renner S. S., Zhang L. B. // Syst. Biol. 2004. Vol. 53. N. 3. P. 422-432.

31. Shaw J. The tortoise and the hare II: relative utility of 21 noncoding chloroplast DNA sequences for phylogenetic analysis / Shaw J., Lickey E. B., Beck J. T., Farmer S. B., Liu W., Miller J., Siripun K. C., Winder C. T., Schilling E. E., Small R. L. // American Journal of Botany. 2005. Vol. 92. P. 142-166.

32. Soranzo N. An example of microsatellite length variation in the mitochondrial genome of conifers / Soranzo N., Provan J., Powell W. // Genome. 1999. Vol. 42. P. $158-161$.

33. Tamura K. MEGA4: Molecular Evolutionary Genetics Analysis (MEGA) software version 4.0 / Tamura K., Dudley J., Nei M., Kumar S. // Molecular Biology and EvolutioN. 2007. Vol. 24. P. 1596-1599.

34. Toor N. Coevolution of group II intron RNA structures with their intron-encoded reverse transcriptases / Toor N., Hausner G., Zimmerly S. // RNA. 2001. Vol.7. P. 1142-1152.

35. Vogel J. Lariat formation and a hydrolytic pathway in plant chloroplast group II intron splicing / Vogel J., Borner T. // EMBO J. 2002. Vol. 21. P. 3794-3803.

36. Won $H$. Horizontal gene transfer from flowering plants to Gnetum / Won H., Renner S. S. // Proc. Natl. Acad. Sci. USA. 2003. Vol. 100. P. 10824-10829.

37. Won H. 2006. Dating dispersal and radiation in the gymnosperm Gnetum (Gnetales) clock calibration when outgroup relationships are uncertain / Won H., Renner S. S. // Syst. Biol. 2006. Vol. 55. N 4. P. 610622 . 
38.Zimmerly S. Phylogenetic relationships among group II intron ORFs / Zimmerly S., Hausner G., Xu-chu W. // Nucleic Acids Res. 2001. Vol. 29. P. 1238-1250.

39.Zuker M. Mfold web server for nucleic acid folding and hybridization prediction / Zuker M. // Nucleic Acids Res. 2003. Vol.31. P.3406-3415.

\title{
CHARACTERIZATION OF VARIABILITY OF THE GENE NAD 1 INTRON IN REPRESENTATIVES OF GENUS VICIA L. (FABACEAE LINDL.)
}

\author{
N. N. Ryzhova, E. A. D'yachenko, M. A. Vishnyakova, \\ E. Z. Kochieva
}

8 SUMMARY: For the first time the sequences of b/c intron of mitochondrial gene $\mathrm{Nad} 1$ have been determined in representatives of $13 \mathrm{Vicia}$ species. It is shown that the sequences of the intron of the gene in these species is highly conservative. In total 23 variable sites and 11 indels have been determined with the intron length 1421-1447 b. p. On the basis of the results of pre-m-RNA intron folding the main elements of its secondary structure have been determined as well as the sites of interdomain interactions. The peculiarities of primary and secondary structure of intron Nad1 in Vicia have been characterized.

KEY WORDS: group II intron; pre-m-RNA; autosplicing; secondary structure; domains; SNPs; indels; Vicia species.

\section{(8) Информация об авторах}

Рыжова Наталья Николаевна - научный сотрудник, кандидат био логических наук, Учреждение Российской академии наук Центр «Биоинженерия» $\mathrm{PAH}$, лаборатория генетической инженерии, группа молекулярных методов анализа генома. 117312, Россия, Москва, пр-т 60-летия Октября, д. 7, корп. 1. E-mail: ekochieva@yandex.ru

Дьяченко Елена Андреевна - студент, Учреждение Российской академии наук Центр «Биоинженерия» РАН, лаборатория генетической инженерии, группа молекулярных методов анализа генома.

117312 , Россия, Москва, пр-т 60-летия Октября, д. 7, корп. 1.

E-mail: ekochieva@yandex.ru

Вишнякова Маргарита Афанасьевна - зав. отделом, доктор биол. наук, с. н. с., ГНУ Всероссийский научно-исследовательский институт растениеводства имени Н. И. Вавилова РАСХН, отдел генетических ресурсов зернобобовых. 190000, Санкт-Петербург,

ул.Большая Морская, 42-44. E-mail: ekochieva@yandex.ru

Кочиева Елена Зауровна - руководитель группы, доктор биол. наук, профессор, Учреждение Российской академии наук Центр «Биоинженерия» $\mathrm{PAH}$

E-mail: ekochieva@yandex.ru
Ryzhova Natalya Nikolaevna - researcher, doctor of biology, Center "Bioengineering", Russian Academy of Sciences, laboratory of genetic engineering, group of molecular methods of genome analysis. 60 let Octyabrya av. 7/1, Moscow, Russia, 117312.

E-mail: ekochieva@yandex.ru

Dyachenko Elena Andreevna — student, Center “Bioengineering”, Russian Academy of Sciences, laboratory of genetic engineering, group of molecular methods of genome analysis.

60 let Octyabrya av. 7/1, Moscow, Russia, 117312.

E-mail: ekochieva@yandex.ru

Vishnyakova Margarita Afanas'evna - chief of the department, professor of biology, senior researcher, N. I. Vavilov All-Russia Institute of Plant Industry, dept. of genetic resources of grain legumes.

42-44, B.Morskaya Street, 190000, St. Petersburg, Russia E-mail: ekochieva@yandex.ru

Kochieva Elena Zaurovna - leader of the group, professor of biology, professor, Center "Bioengineering”, Russian Academy of Sciences, laboratory of genetic engineering, group of molecular methods of genome analysis. 60 let Octyabrya av. 7/1, Moscow, Russia, 117312.

E-mail: ekochieva@yandex.ru 